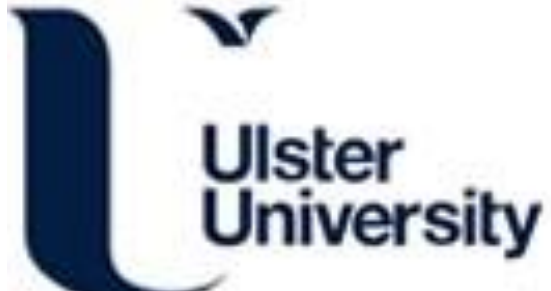

\section{The communication experiences of education managers: Identifying strengths, weaknesses and critical incidents}

Hunt, O., Tourish, D., \& Hargie, O. (2000). The communication experiences of education managers: Identifying strengths, weaknesses and critical incidents. International Journal of Educational Management, 14(3), 120-129.

Link to publication record in Ulster University Research Portal

\section{Published in:}

International Journal of Educational Management

Publication Status:

Published (in print/issue): 01/01/2000

\section{Document Version}

Publisher's PDF, also known as Version of record

\section{General rights}

Copyright for the publications made accessible via Ulster University's Research Portal is retained by the author(s) and / or other copyright owners and it is a condition of accessing these publications that users recognise and abide by the legal requirements associated with these rights.

\section{Take down policy}

The Research Portal is Ulster University's institutional repository that provides access to Ulster's research outputs. Every effort has been made to ensure that content in the Research Portal does not infringe any person's rights, or applicable UK laws. If you discover content in the Research Portal that you believe breaches copyright or violates any law, please contact pure-support@ulster.ac.uk. 


\title{
The communication experiences of education managers: identifying strengths, weaknesses and critical incidents
}

\author{
Orlagh Hunt \\ Queen's University of Belfast, Northern Ireland \\ Dennis Tourish \\ School of Psychology and Communication, University of Ulster, Northern Ireland \\ Owen D.W. Hargie \\ School of Psychology and Communication, University of Ulster, Northern Ireland
}

\section{Keywords}

Communication, Education,

Management, Corporate culture

\section{Abstract}

Education managers from various education settings were asked to record the three most typical work-related incidents of communication within a specified timeframe. They were also asked to identify the strengths and weaknesses of communication prac-

tices at work. The resultant data provide insight into the existing communication climate within education organisations, and the problems which need to be overcome. Specifically, the main findings were of persistent

communication problems between managers and staff, the organisation of meetings, the transmission of information and the use of appropriate communication channels. The data suggest that there is a need for improved communication to facilitate the more effective management of education organisations, and to improve relationships between education managers and their staff. Greater communication skills training for managers is therefore recommended. This paper also considers areas where further research is indicated.
The International Journal of Educational Management 14/3 [2000] 120-129

(C) MCB University Press [ISSN 0951-354X]

\section{Introduction}

While there is a vast range of literature in the fields of communication, management and education, there is a dearth of research which specifically investigates communication as related to education managers. Given that communication is an essential aspect of the manager's role as a leader (Harris, 1998), and that effective leadership creates effective schools (Thody, 1998), this neglect is surprising. It is with this focus in mind that the current study was designed to bring together existing knowledge in these fields in an attempt to advance understanding of the role of communication within education management.

The communication process in organisations is a complicated one; complicated by the fact that we as individuals have our idiosyncrasies, biases, and abilities, and complicated by organisational characteristics such as hierarchy or specialisation (Smeltzer, 1996). However, communication is the process most central to the success or failure of an organization (Hargie et al., 1999). It is through communication of one kind or another that employees learn what is expected of them, find out how to do their jobs, and become aware of what others think of their work (Orpen, 1997).

As with most organizations, education establishments engage in a wide variety of communications on a daily basis. Some messages are individually specific - for example, a principal giving feedback on a completed task or requesting information on a student. Others are team or group-oriented - for example, defining current group objectives or sharing plans for the week. Thus, it is clear that interpersonal

The current issue and full text archive of this journal is available at http://www.emerald-library.com communication is central to the work of education organizations, and especially to the role of the education manager. However, research into managerial communication, and more specifically education management communication, is at an early stage.

Management is about crafting a strategic vision to enhance organisational effectiveness, and requires the effective use of the tools of communication. Luthans and Larsen (1986) found that managers typically spend between 60 per cent and 80 per cent of their time communicating. However, Hargie et al. (1994) noted that managers generally overrate the effective use of their interpersonal communication skills. Specifically, they argued that education managers need to acquire and develop specialist communication skills and learn how to apply these to particular situations within their organization.

Organizational communication scholars have more recently focused on the communication climate of organisations. Kreps (1990) described this as the internal emotional tone of the organisation, based on how comfortable members feel with one another and with the organisation. The climate develops out of the behaviours and policies of organisation administrators and the specific communication behaviours of organisation members. Friendly climates encourage members to communicate in an open, relaxed and convivial manner with work colleagues, while negative climates discourage open and facilitative communication. Hence, communication is not just important from the functional point of view of getting the message across, it is also central to the development and maintenance of positive working relationships, harmony and trust.

Communication has also been found to be related to variables such as burnout, stress and social support (Ray, 1993; Tutteman and Punch, 1992; Somers and Lefkowitz, 1983). In a study of 135 managers from 21 different 
Orlagh Hunt, Dennis Tourish and Owen D.W. Hargie

The communication

experiences of education

managers: identifying

strengths, weaknesses and

critical incidents

The International Journal of

Educational Management

14/3 [2000] 120-129 firms in the UK, Orpen (1997) found that both job satisfaction and work motivation were positively affected by the quality of communication within their firms. Conversely, where communication is dysfunctional, the incidence of staff illness, turnover and litigation have been shown to increase (Hargie et al., 1999). Therefore, improving flow of communication within companies should raise both manager and employee motivation and satisfaction. Management clearly has the main responsibility to influence this situation.

Organisational communication is only as good as interpersonal communication (Torrington and Weightman, 1994). Whatever initiatives are taken to improve the former, they will only be as good as the quality of the latter. Managerial communication is probably one of the most critical areas of organisational communication in general and it is the point at which managerial behaviour can genuinely make a difference in influencing performance and employee attitudes (Klaus and Bass, 1982).

Certainly as an activity for managers, communication occupies a vast majority of a manager's time, and thus any increase in a manager's effectiveness or skill as a communicator should contribute directly or indirectly to improved organisational performance (Torrington and Weightman, 1994).

The current state of knowledge in this area, however, is relatively fragmented, especially in terms of understanding specifically what communication situations characterise current work practices, and the contribution that effective interpersonal communication can make to improving individual and organisational performance. This study will investigate what education managers themselves feel to be the key dimensions of communication.

The purpose of the study is threefold. First, it aims to highlight predominant patterns of communication incidents occurring in the workplace by focusing on specific communication skills employed, problem solving skills and the context of communication incidents. Second, the study explores respondents' perceptions of communication processes in the workplace. Third, it is concerned with identifying the current communication climate in education management. The overall intention was to ascertain what managers believed to be the obstacles faced at present, and the measures most likely to overcome these hurdles.

\section{Method \\ Participants}

Twenty-eight education managers took part in this study. They consisted of six principals, three vice-principals, and 19 heads of department, all of whom were completing an MSc course in education management.

\section{Procedure}

Participants were asked to record on paper:

- three critical incidents that occurred during the course of their work, and

- a summary of the main strengths and weaknesses of communication within their organisation.

The critical incident technique is a widely used research methodology. It was pioneered by Flanagan $(1948 ; 1954)$, who developed it as a means of gathering concrete instances of effective and ineffective behaviour in any context. It is based upon the perspective that internal feelings of satisfaction or dissatisfaction with a person stem from actual incidents in real life. These attitudes in turn influence how future encounters are "seen", categorised, and responded to (Hargie and Tourish, in press).

The critical incident procedure itself involves three main phases (Caves, 1988):

1 defining the target population;

2 obtaining the description of incidents; and

3 identifying the competencies.

In this study, the target population of education managers were instructed to choose three critical incidents which occurred during the time they were enrolled in a semester of an MSc course in education management (approximately a 12 week period). The descriptions of incidents were obtained by asking them to provide detailed written accounts of these events in as much detail as possible. In particular, they had to detail what led up to the incidents, people involved, communication skills employed, difficulties encountered, and the outcome of the incidents.

With regard to the strengths and weaknesses of communication within the workplace, participants were also asked to give an overall picture of communication by considering current strengths and weaknesses, management style, and communication channels.

Participants completed these accounts in their own time within a three month timeframe. 
Orlagh Hunt, Dennis Tourish and Owen D.W. Hargie

The communication

experiences of education

managers: identifying

strengths, weaknesses and

critical incidents

The International Journal of

Educational Management

14/3 [2000] 120-129

\section{Data analysis}

All of the data were analysed using content analysis. The overall purpose of the content analysis approach is to identify specific recurring characteristics from data systematically and objectively in order to shape raw material into meaningful categories. This method requires that key content areas are identified by the researcher, followed by the allocation of individual constructs to each of these categories (Stewart and Stewart, 1981). Increasingly, researchers are utilising this method to develop complex, thematic analyses of transcripts that combine interpretative sensitivity with systematic coding (Hoijer, 1990; Kepplinger, 1989; Liebes and Katz, 1990; Livingstone and Lunt, 1994).

The written data in this study were read and re-read by the authors until thorough familiarity with the work was achieved. Common themes were then identified from the written accounts, at both main category and sub-category levels.

The contents of the communication incidents as described by respondents were classified into major categories. Once the framework for the content analysis had been constructed, all of the replies were coded within this. The data were examined for the frequency with which the different communication incidents were mentioned by the participants. The same procedure was used to content analyse the strengths and weaknesses of communication in the workplace as described by the participants.

\section{Results}

Sixty-four communication incidents were reported in total (i.e. not all respondents reported three incidents). The incidents were initially content analysed by considering six major categories that emerged through initial analysis of the transcripts. The categories were:

1 nature of the incident;

2 communication flow;

3 others involved;

4 difficulties encountered;

5 communication skills employed, and

6 outcome of the incident.

The framework for the content analysis was further sharpened by the identification of sub-categories within each of the above six areas (see Table I). All of the communication incidents were then coded using this system.

\section{Nature of the incident}

The majority of communication incidents reported were formal and work related.
Overall, meetings were the most frequent setting within which the communication incidents occurred (63 per cent) (see Table II).

In some cases the meeting was not arranged but occurred by chance (11 per cent). Where this was the case, respondents expressed concern at the location and timing of the incidents ( 6 per cent). Interruptions were an underlying concern and often issues were not debated to a solution as time did not permit.

I felt rushed and couldn't get my point across.

I think I was forced into a decision because

there wasn't enough time.

On the other hand, 5 per cent of respondents who reported an unplanned communication incident noted the advantages associated with this type of encounter. Simple issues remained uncomplicated and it allowed for greater development of personal relationships.

I was glad we didn't make a big deal of this and as a result I think we avoided further complications.

The majority of meetings, however, were prearranged (88 per cent). From the incidents reported, there was a clear pattern regarding size of meetings. Large numbers tended to complicate the issue at hand and resulted in situations not being resolved. Respondents noted that the timing of the meeting influenced its success (25 per cent). For example, when meetings were held in schools after working hours, respondents reported being tired and unable to concentrate. These meetings tended to be rushed for the sake of getting home and resulted in issues not being discussed properly.

I don't think it's a good idea to hold meetings after work. Everyone is too tired and irritable.

Where a meeting involved people who were friends as well as colleagues, there was a mutual respect, which seemed to surpass any underlying difficulty with work issues. This led to greater success in resolving work situations. Also, the style of communication in this case was interpreted as slightly less formal than communication with strictly working colleagues.

Of the respondents, 19 per cent reported communication incidents that did not take the format of a meeting. These encounters concerned conferences, advice giving, dealing with complaints, and handling situations as they arose. Written communication was reported by 7 per cent of the respondents. This was seen as satisfactory but usually required follow-up communication of a different nature (i.e. face-to-face meeting, telephone call). 

and Owen D.W. Hargie

The communication

experiences of education

managers: identifying

strengths, weaknesses and

critical incidents

The International Journal of

Educational Management

14/3 [2000] 120-129
Orlagh Hunt, Dennis Tourish

\section{Direction of communication flow}

Downward communication (from a superior to a subordinate) was reported in 37 per cent of the cases (see Table III). Upward communication (from subordinate to superior) was reported by 29 per cent of the participants, while lateral communication was described in 15 per cent of the incidents. A large proportion of the incidents involved groups of people from all levels within the particular education establishment. These accounted for 19 per cent of the communication incidents; 6 per cent of incidents concerned communication with non-colleagues.

Of note was the trend for individuals in the most senior position within their organisation (i.e. principal) to report communication flow in the same direction for incidents they reported. In the case of

\section{$\overline{\text { Table } 1}$}

Communication incidents: identified categories and sub-categories

\begin{tabular}{ll}
\hline Category & Sub-category \\
\hline Nature of the incident & $\begin{array}{l}\text { Formal meeting, informal meeting, chat, } \\
\text { conference, written communication, discussion, } \\
\text { telephone call }\end{array}$ \\
Communication flow & $\begin{array}{l}\text { Onnward, upward, lateral, group communication } \\
\text { Others involved }\end{array}$ \\
Difficulties involved & Not aware of situation, bad atmosphere, conflicting \\
& $\begin{array}{l}\text { opinions, lack of time, wrong location, personal } \\
\text { conflict } \\
\text { Communication skills }\end{array}$ \\
Vutcome of incident & communication skills \\
& Fully resolved, partially resolved, not resolved, no \\
& attempt to resolve
\end{tabular}

\section{$\overline{\text { Table II }}$}

Nature of communication incident

\begin{tabular}{lcc}
\hline $\begin{array}{l}\text { Communication } \\
\text { incident }\end{array}$ & No. of cases & $\%$ of cases \\
\hline Meeting & 40 & 63 \\
Conference & 12 & 19 \\
Chat & 7 & 11 \\
Written & 5 & 7 \\
Total incidents & 64 & 100
\end{tabular}

\section{$\overline{\text { Table III }}$}

Direction of communication flow within incidents

\begin{tabular}{lcc}
\hline Direction & No. of incidents & $\%$ of cases \\
\hline Downward & 24 & 37 \\
Upward & 14 & 22 \\
Lateral & 10 & 15 \\
Group & 12 & 19 \\
Other & 4 & 6 \\
Total & 64 & 100
\end{tabular}

respondents who were principals, all reported communication was downward.

\section{People involved in communication incidents}

Of the incidents, 49 per cent involved encounters which were one-to one while 42 per cent took place during staff meetings (see Table IV). The remainder of incidents (9 per cent) involved more than three members of staff but did not constitute a staff meeting.

In incidents that involved more than two people, respondents tended to report that the process of resolution was slow and directly attributed this to the fact that it was not a one-to-one communication incident.

Everything seems to take so much longer when it's a meeting with the whole department. I think things can be sorted out much faster when less people are involved.

Another feature of communication involving larger groups of people was that respondents reported feeling uncomfortable addressing a large meeting and often stayed quiet rather than speaking out. Such communication incidents were regarded as more time consuming and required greater preparation. Large meetings often resulted in some members continuing to debate issues in smaller groups after the official meeting ended, resulting in gossip and speculation.

People seemed to form small groups after the meeting and continued to discuss the issues.

In fact, there appeared to be quite a lot of bad feeling.

When an incident was reported that involved two or more people that had dealt with a similar problem, or resolved situations amicably before, this seemed to affect the outcome of the current difficulty for the better. Bad previous relationships or unresolved problems hindered success in the present situation.

We had encountered this before, so I think we both knew what way to handle it.

\section{Communication difficulties encountered} Table V highlights the items that were described most often as "difficult"

\section{Table IV}

Others involved in communication incident

\begin{tabular}{lcc}
\hline People involved & $\begin{array}{c}\text { No. of } \\
\text { respondents }\end{array}$ & \% of cases \\
\hline One-to-one & 31 & 49 \\
Three or more $^{\text {a }}$ & 6 & 9 \\
Staff meeting $_{\text {Total }}$ & 27 & 42 \\
& 64 & 100
\end{tabular}

Note: ${ }^{a}$ A meeting involving three or more people that is not a staff meeting 
Orlagh Hunt, Dennis Tourish and Owen D.W. Hargie

The communication

experiences of education

managers: identifying

strengths, weaknesses and

critical incidents

The International Journal of

Educational Management

14/3 [2000] 120-129 $\overline{\text { Table V }}$

Difficulties encountered during communication incident

\begin{tabular}{lc}
\hline Difficulty & No. of cases $^{\mathbf{a}}$ \\
\hline Not aware of situation & 9 \\
Bad atmosphere & 7 \\
Conflicting opinions & 7 \\
Lack of time & 6 \\
Wrong location & 6 \\
Personal conflict & 6
\end{tabular}

a Not all respondents reported difficulties and some respondents reported more than one difficulty per incident

surrounding the communication incident. Not being aware of the situation in advance of the communication taking place greatly affected the handling of communication incidents. If individuals did not have the full facts surrounding an issue, decision making became difficult. A bad atmosphere and conflicting opinions occurred equally as difficulties.

Where the incident took place greatly influenced the outcome. When a meeting was officially arranged (agenda circulated etc.), it was reported as running more smoothly. In some cases it was the norm to provide refreshments at meetings (tea/coffee) and to begin in a relaxed fashion. Unplanned meetings often took place in the school corridor or over lunch in the staff room (i.e. the wrong location). This was more often than not felt to be unsatisfactory as it resulted in interruptions and little time to discuss matters in detail. However, on one occasion it was considered better that a sensitive issue was handled in this way as it could have been complicated by formality.

I'm glad we sorted it out there and didn't take the matter any further.

Other items mentioned were:

- a simple situation being made complicated;

- poor communication with other party;

- anxiety over the situation;

- poor communication by the respondent;

- interruptions; and

- no agenda for a meeting.

\section{Outcome of the incidents}

Of the situations, 48 per cent were described as resolved or brought to a conclusion (see Table VI). Where situations were only partially resolved (24 per cent), the incidents primarily concerned a meeting with more than two people. In contrast, the incidents that were fully resolved involved mainly oneto-one encounters. Large meetings (e.g. staff meetings) tended not to result in a final
Table VI

Outcome of the incident

\begin{tabular}{lcc}
\hline Communication incident & $\begin{array}{c}\text { No. of } \\
\text { cases }\end{array}$ & $\begin{array}{c}\text { \% of } \\
\text { cases }\end{array}$ \\
\hline Fully resolved & 31 & 48 \\
Partially resolved & 15 & 24 \\
Not resolved & 16 & 25 \\
No attempt to resolve & 2 & 3 \\
Total & 64 & 100 \\
\hline
\end{tabular}

decision. With smaller one-to-one interactions, outcomes tended to be more immediate.

\section{Communication strengths and weaknesses in the workplace}

It was considered important to take into account the communication climate that the respondents work in and within which the communication incidents occurred. Therefore, the respondents provided a summary of the perceived strengths and weaknesses of communication in their workplace. The summaries were initially classified into four major categories, namely, communication flow, management communication style, specific weaknesses in communication and specific strengths in communication. Once the framework for the content analysis had been constructed, all the summaries were coded using the categories represented in Table VII.

\section{Communication flow}

Upward, downward and lateral communication were evident and often a combination of all three were utilised on a daily basis in any one workplace. Table VIII shows the number of times that each was reported.

Communication in an upward direction featured most often but was regarded as primarily unsatisfactory (63 per cent) by those who cited it. Communication in a downward direction was reported by 26 per cent of respondents, and was described as poor by the majority, with only 20 per cent of those considering it as satisfactory. Lateral communication was described as either formal or informal. Where the respondent was in a less senior position (i.e. not employed as a head of department or principal), lateral communication was primarily informal. Formal lateral communication was predominant among respondents who held senior positions within the workplace.

\section{Management communication style} Respondents identified one of two types of management style in the workplace. A 
Orlagh Hunt, Dennis Tourish and Owen D.W. Hargie

The communication

experiences of education

managers: identifying

strengths, weaknesses and

critical incidents

The International Journal of

Educational Management

14/3 [2000] 120-129 hierarchical style was reported by 53 per cent of participants, while a flatter style of management was reported by 47 per cent of participants (see Table IX). Where a flatter style of management was described, it was a relatively new procedure and was a change from a previously hierarchical style of management. This flatter style of communication was not always seen as an improvement on the previous management style.

\section{Specific weaknesses in communication}

Overall, there were more than twice as many weaknesses in communication (54) reported than strengths in communication (26) (see

Table X). The most common weaknesses were where the respondent did not have the forum to express an opinion, poor dissemination of information by others and lack of time for communication. Other weaknesses mentioned less frequently were large school size, previous strained relationships, overloaded meeting agenda and wrong location.

\section{$\overline{\text { Table VII }}$}

Communication in the workplace: identified categories and sub-categories

\begin{tabular}{ll}
\hline Categories & Sub-categories \\
\hline Direction of communication & Downward, upward, lateral \\
Management style & Flat, hierarchical \\
Weakness in communication & Expression of opinion, dissemination of information, \\
& lack of time, isolation, management style, lack of \\
& consistency, poor personal interaction \\
Strengths in communication & Meetings, communication recognised, approachable \\
& principal, opinion respected
\end{tabular}

$\overline{\text { Table VIII }}$

Direction of flow of communication within workplace

\begin{tabular}{lcc}
\hline Direction & $\begin{array}{c}\text { No. of times } \\
\text { reported }\end{array}$ & $\%$ of cases \\
\hline Upward & $19^{a}$ & 48 \\
Downward & $10^{a}$ & 26 \\
Lateral & $10^{a}$ & 26
\end{tabular}

Note: ${ }^{a}$ Some respondents described communication flowing in more than one direction

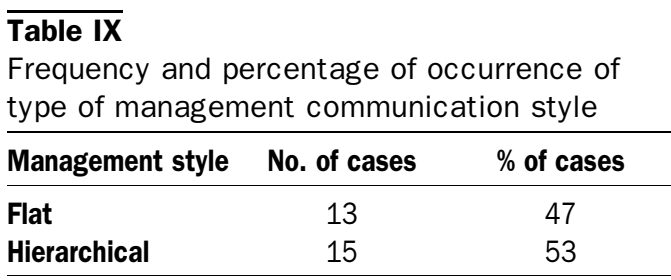

\section{Communication strengths}

Respondents described the specific strengths in communication in their workplace (see Table XI). Staff meetings were seen as one of the best ways to discuss issues and resolve problem situations (31 per cent). Again, such meetings were perceived to be more productive when an agenda was circulated on time, thereby allowing people to prepare for issues raised. Communication was viewed as good when staff at all levels were asked to contribute their ideas openly. Other strengths of communication described were trust among staff, good interpersonal skills and introducing new methods of communication.

\section{Discussion}

This study has provided insight into the views of education managers with regard to communication practices and processes in the working environment. The data illuminate the communication climate within which today's education managers work. They also uncover predominant patterns of communication incidents occurring in the workplace, and the respondents' perceptions of the main influencing factors which determine success or failure.

As expected and in line with previous research, communication was viewed by the

\section{$\overline{\text { Table X }}$}

Most frequently reported communication weaknesses

\begin{tabular}{lcc}
\hline Weakness & No. of cases & $\%$ of cases \\
\hline Expression of opinion & 7 & 13 \\
$\begin{array}{l}\text { Dissemination of } \\
\quad \text { information }\end{array}$ & 7 & 13 \\
Not enough time & 6 & 11 \\
Isolation & 6 & 11 \\
Management style & 6 & 11 \\
Lack of consistency & 4 & 7 \\
Poor personal interaction & 4 & 7 \\
Other & 14 & 26 \\
\hline
\end{tabular}

\section{$\overline{\text { Table XI }}$}

Most frequently reported communication strengths

\begin{tabular}{lcc}
\hline Strength & No. of cases & $\%$ of cases \\
\hline Meetings & 8 & 31 \\
Communication & & \\
$\quad$ recognised & 4 & 15 \\
Approachable principal & 4 & 15 \\
Opinion respected & 4 & 15 \\
Other & 6 & 24
\end{tabular}


Orlagh Hunt, Dennis Tourish and Owen D.W. Hargie

The communication

experiences of education

managers: identifying

strengths, weaknesses and

critical incidents

The International Journal of

Educational Management

14/3 [2000] 120-129 majority of respondents as fundamental to the role of the education manager. A meeting was the situation where the majority of interpersonal communication incidents occurred (63 per cent). One of the main components of a good communication channel is the regular staff meeting (Hargie et al., 1999). Unfortunately, the word "meeting" has negative connotations for some and this important tool is often not used to its potential. But good planning can reinstate the meeting to the central place of importance that employees think it deserves.

Participants in this study found that planned meetings were ultimately more successful than unplanned encounters and also that larger meetings were less productive. This is in line with previous research by Gagnon (1988) which suggests that it is impossible to have a good meeting with, for example, 20 people. He found that proper give and take did not occur when too many people were present and instead suggested that five or six may be the ideal number. This research suggests that education managers do not take sufficient advantage of such findings in their own conduct of meetings.

Frustrations with meetings often can be attributed to the fact that "nothing ever happens" as a result. This was a sentiment expressed by the participants, who felt that frustration could be avoided if there is more preparation on everyone's behalf (for example, agenda circulated in advance, enough time to discuss all issues raised). If productive staff meetings are held, a chain of communication can be initiated that can be replicated the whole way down the line.

\section{Direction of communication}

Argyle (1991, p. 16) noted that "co-operation over work or relationships could not occur at all without communication and social interaction". To be effective, communications must be multi-directional, from management down, from operating levels up and from staff to staff (Reitzfeld, 1989). Of the communication incidents described in the present study, 19 per cent involved members from all positions within the educational system. This suggests that there is some movement away from a completely hierarchical style within the educational sector. Many authors believe this to be a vital move for all organisations (Kane, 1996; Smith, 1990). In fact some go so far as to say that the traditional authoritarian style of management with its emphasis on one-way communication between superiors and subordinates simply has no place in the modern working environment (Wah, 1998; Kane, 1996).

An effective system of communication between employees and management can overcome obstacles to the satisfactory flow of information. The steps involved in developing an effective communication system include making communication a fundamental component of the management role, obtaining the commitment of top management, and evaluating the communication process of all its members on a regular basis (Smith, 1990).

Management must see two-way communication not as a bothersome task, but as a fundamental means of helping to release the valuable opinions of all employees. The difficulty is that changing established patterns of human behaviour is not easy. According to the present study, employees want to know what is expected of them. Without this type of understanding, most employees will simply not be willing, or know how, to modify established attitudes and work behaviour required to make changes successful and personally rewarding (Smith, 1990).

\section{People involved}

The majority of incidents reported were oneto-one. These were resolved more quickly than incidents involving more than two people. Again, when more than two people were involved, time limited the topics that could be discussed by everyone and issues of individual differences interfered. This suggests that further communication skills training, focusing on group dynamics and negotiation skills, would be of benefit.

Some 42 per cent of the reported incidents surrounded staff meetings. Many of the participants felt they lacked confidence to speak out at larger staff meetings. Training targeted at meeting the communication needs of such participants so they feel able to contribute ideas would be useful for such situations. Participants did perceive some meetings as leading to the formation of subgroups. Participants wanted the opportunity to have "their say". It would therefore, be, more useful to change the format of meetings by, for example, forming smaller groups to discuss ideas and then collaborating on suggestions that arise from these.

Previous success in solving difficulties was seen by the participants as a good indicator of resolving future issues with the same individual(s). Sandwith (1994, p. 56) noted that managers and employees can become "wedded to our ways". More awareness of the different communication styles that exist by all involved could be the key to making 
Orlagh Hunt, Dennis Tourish and Owen D.W. Hargie

The communication

experiences of education

managers: identifying

strengths, weaknesses and

critical incidents

The International Journal of

Educational Management

14/3 [2000] 120-129 communication more successful as well as helping individuals to determine the most appropriate style to use for different individuals.

The participants here felt that personality interfered with how one handles various situations. In recent years industrial organisational psychologists have paid increasing attention to the mediating role of individual difference (personality) variables that affect people's reactions to their work experiences. Treating all employees alike is unlikely to achieve the desired result because people respond differently to different approaches. However, stereotyped communication and learning styles may be useful as a baseline upon which managers can develop a style that is appropriate for each individual worker (Peak, 1995).

\section{Difficulties encountered}

A lack of time affected the quality of communication of many participants. While they did appreciate that the role of the manager is a busy one, many respondents felt that managers often let communication skills slide for the sake of reaching a speedy conclusion (i.e. not asking everyone involved, making a decision without agreement, allowing the situation to deteriorate before dealing with it). Two surveys reported by Wah (1998) indicated that the creative ideas of workers are often under-utilised because managers do not pay enough attention to them. The findings in this study suggest that this may often occur because there is a lack of venue and time to share ideas.

Insufficient communication between management and employees sometimes leads to employee confusion on how to achieve goals, although they are aware of what these goals are (Hargie, 1997). Expert communication skills in handling awkward situations and dealing with situations that arise suddenly would help. Ward (1997) found that when employees perceive that management is receptive to suggestions and willing to change when a suggestion is useful, employees are more satisfied. The location of incidents is important in such situations. Encounters that take place in the school corridor or over lunch are not ideal since minimal opportunity exists for a single minded focus on the issue and the achievement of a satisfactory outcome. Managers need to learn how to handle situations such as these, that arise suddenly.

\section{Outcome of the incidents}

Of the incidents, 48 per cent were described as resolved by the participants. These were primarily one-to-one encounters. Again, this would appear to reinforce the preference of participants for smaller meetings. One quarter of the incidents were not resolved at all while 24 per cent were partially resolved. The partially resolved incidents tended to involve more than two staff members.

These findings would indicate that face-toface meetings are the most popular method of communicating within an education setting, but participants' experience of meetings suggests that the format and structure could be improved for maximum success. Also, more time is essential for managers to be able to deal effectively with situations, with the location of the incident seen as equally important.

\section{Strengths and weaknesses of communication in the workplace} The strengths and weaknesses of communication highlighted when participants described the communication incidents were very similar to those they highlighted when discussing the current state of communication within their workplace. Twice as many weaknesses in communication as strengths were outlined. This indicates that there is substantial room for improvements in communication in the education environment at present. The main weaknesses were that participants wanted to feel more able to express their opinion, a lack of time, large school size and wrong location. The major strength of communication in the workplace was meetings. However, it must be noted that participants did feel that the format and make-up of the meeting could be improved. Participants again reiterated that they wanted to be asked to contribute ideas and have a chance to express their opinions.

The predominant direction of communication was upward. However, communication in all directions was seen as unsatisfactory overall. Participants reported being unhappy with the management style in their workplace regardless of whether it was hierarchical or a flatter style of management.

Trust among staff was also seen as vital to successful communication. This can be built up by informing employees of all events within the workplace and valuing their opinion. Lee (1997) argues that the system of superior-subordinate relationships exists within and is influenced by its larger organisational system. Over the past two decades organisational communication scholars have devoted increasing attention to the study of social support in the workplace. Berlin Ray (1993) suggested that research examines supportive communication as it is situated in the particular context of the 
Orlagh Hunt, Dennis Tourish and Owen D.W. Hargie

The communication

experiences of education

managers: identifying

strengths, weaknesses and

critical incidents

The International Journal of

Educational Management

14/3 [2000] 120-129 workplace, and how it may impact upon work-life variables such as job stress and burnout.

\section{Conclusions and implications}

The communication experiences and skill needs of education managers which have been highlighted here mean that management training can be targeted more precisely to meet identified needs and difficulties. This also will lead to suggestions for further research to look at why these particular difficulties are arising in the first place. These findings have implications for practising managers, particularly with respect to training educators for their role as managers.

It was apparent from the results of this investigation that education managers are involved in a wide range of activities on a daily basis in which interpersonal communication occupies an important role. While all of the participants had communication skills which they felt were proficient, they were able to identify other areas where improvement could be achieved.

Good communication in the workplace results in mutual understanding, harmony and action while poor communication only wastes time and resources, forestalls goal accomplishment and sours relationships (Sandwith, 1994). Once we understand why communication fails, we can identify why things have gone wrong. This study makes a contribution to the identification and analysis of the interpersonal and management skills needed by education managers within commonly occurring situations. While it is well known that communication styles cannot be designated correct or incorrect, but only effective or ineffective (Peak, 1995), this study has brought research in this area a step further by determining managers' perceptions of the effectiveness of both their own communication and that of their workplace in general.

\section{References}

Argyle, M. (1991), Co-operation: The Basis of Sociability, Routledge, London.

Berlin Ray, E. (1993), "When the links become chains: considering dysfunctions of supportive communication in the workplace", Communication Monographs, Vol. 60, pp. 106-12.

Caves, R. (1988), "Consultative methods for extracting expert knowledge about professional competence", in Ellis, R. (Ed.), Professional Competence and Quality
Assurance in the Caring Professions, Crook Helm, London.

Flanagan, J.C. (1954), “The critical incident technique”, Psychological Bulletin, July, Vol. 51 No. 4, pp. 327-58.

Gagnon, G. (1988), "Meetings are manager's key to communication", Transportation and Distribution, Vol. 29 No. 5, p. 61.

Hargie, C., Tourish, D. and Hargie, O. (1994), "Managers communicating: an investigation of core difficulties within educational organisations", International Journal of Educational Management, Vol. 8 No. 6, pp. 23-8.

Hargie, O. (Ed.) (1997), The Handbook of Communication Skills, Routledge, London.

Hargie, O. and Tourish, D. (in press), The Handbook of Communication Audits for Organizations, Routledge, London.

Hargie, O., Dickson, D. and Tourish, D. (1999), Communication in Management, Gower, Aldershot.

Harris, A. (1998), "Improving ineffective departments in secondary schools", Educational Management and Administration, Vol. 26 No. 3, pp. 269-77.

Hoijer, B. (1990), "Studying viewer's reception of television programmes: theoretical and methodological considerations", European Journal of Communication, Vol. 5 No. 1, pp. 29-56.

Kane, P. (1996), "Two-way communication fosters greater commitment”, HR Magazine, Vol. 41 No. 10 , pp. 50-2.

Kepplinger, H. (1989), "Content analysis and reception analysis", American Behavioral Scientist, Vol. 33 No. 2, pp. 172-82.

Klaus, R. and Bass, B. (1982), Interpersonal Communication in Organisations, Academic Press, New York, NY.

Kreps, G. (1990), Organisational Communication: Theory and Practice 2nd ed., Longman, London.

Lee, J. (1997), "Leader-member exchange, the 'pelz effect', and co-operative communication between group members", Management Communication Quarterly, Vol. 11 No. 2, pp. 266-87.

Liebes, T. and Katz, E. (1990), The Export of Meaning, Oxford University Press, Oxford.

Livingstone, S. and Lunt, P. (1994), Talk on Television: The Critical Reception of Audience Discussion Programs, Routledge, London.

Luthans, F. and Larsen, J. (1986), "How managers really communicate", Human Relations, Vol. 39, pp. 161-78.

Orpen, C. (1997), "The interactive effects of communication quality and job involvement on managerial job satisfaction and work motivation”, Journal of Psychology, Vol. 131 No. 5, pp. 519-22.

Peak, M. (1995), "Can we talk: one-size-fits-all doesn't work when it comes to communications and learning styles", Management Review, Vol. 84 No. 2, p. 1. 
Orlagh Hunt, Dennis Tourish and Owen D.W. Hargie

The communication

experiences of education

managers: identifying

strengths, weaknesses and

critical incidents

The International Journal of

Educational Management

14/3 [2000] 120-129
Reitzfeld, M. (1989), “Improving a firm's communications", Journal of Systems Management, Vol. 40 No. 6, p. 18.

Sandwith, P. (1994), "Building quality into communications", Training and Development, Vol. 48 No. 1, pp. 55-9.

Smeltzer, L. (1996), "Communication within the manager's context", Management Communication Quarterly, Vol. 10 No. 1, pp. 5-26.

Smith, A. (1990), "Bridging the gap between employees and management", Public Relations Journal, Vol. 46 No. 11, pp. 20-2.

Somers, M. and Lefkowitz, J. (1983), "Self-esteem, need gratification, and work satisfaction: a test of competing explanations from consistency theory and self-enhancement theory", Journal of Vocational Behaviour, Vol. 22, pp. 303-11.

Stewart, V. and Stewart. A. (1981), Business Applications of Repertory Grid, McGraw Hill, London.

Thody, A. (1998), "Training school principals, educating school governors", International
Journal of Educational Management, Vol. 12 No. 5, pp. 232-9.

Torrington, D. and Weightman, J. (1994), Effective Management: People and Organisations, Prentice Hall, London.

Tutteman, E. and Punch, K. (1992), “Teachers' psychological distress: the ameliorating effects of control over the work environment”, Educational Review, Vol. 44 No. 2, pp. 181-94.

Wah, L. (1998), "Good ideas go unheard", Management Review, Vol. 87 No. 2, p. 7.

Ward, E. (1997), "Autonomous work groups: a field study of correlates of satisfaction", Psychological Reports, Vol. 80 No. 2, pp. 60-2.

\section{Further reading}

Euske, N. and Roberts, K. (1987), "Evolving perspectives in organisational theory: communication implications", in Jablin, F.M., Putnam, L.L., Roberts, K.H. and Porter, L.W. (Eds), Handbook of Organisational Communication: An Interdisciplinary Perspective, Sage, Beverly Hills, CA, pp. 41-69. 